\title{
COVID-19 КАК ЗООНОЗНАЯ ИНФЕКЦИЯ
}

\author{
А.Н. Куличенко, О.В. Малецкая, Н.С. Саркисян, А.С. Волынкина \\ ФКУЗ Ставропольский противочумный институт Роспотребнадзора, г. Ставрополь, Россия
}

Резюме. В статье рассматриваются вопросы соответствия новой коронавирусной инфекции COVID-19 зоонозам на основании данных о вероятном происхождении вируса SARS-CoV-2, возможном формировании его резервуара в организме животных (летучих мышей) и восприимчивости к нему человека. Сегодня преобладает точка зрения, что вспышка COVID-19 возникла в результате преодоления коронавирусом SARS-CoV-2 межвидового барьера, приобретения способности инфицировать человека и распространяться в этой популяции. Сравнительный филогенетический анализ на молекулярном уровне показал, что SARS-CoV-2 генетически наиболее близок к коронавирусам летучих мышей, в частности к штаммам RmYN02 и RaTG13, изолированным от подковообразной летучей мыши - вида, считающегося основным хозяином коронавирусов SARS-CoV и MERS-CoV. Выявлена способность коронавируса SARS-CoV-2 инфицировать различные виды диких животных. SARS-CoV-2 был обнаружен у норок на фермах в странах Западной Европы и США, смертность составила от 1,2 до 2,4\%. При инфицировании коронавирусом SARS-CoV-2 макак-резусов у них имела место продуктивная инфекция, была обнаружена виремия. Установлено, что кошки являются восприимчивыми хозяевами человеческого вируса SARS-CoV-2. Вероятное объяснение этому кроется в высокой степени сходства между человеческими и кошачьими формами рецептора АCE2. Также показано, что собаки могут заразиться, но не передают вирус другим животным. На сегодняшний день Всемирная организация по охране здоровья животных за весь период пандемии не располагает сведениями о случаях заражения человека от домашних питомцев. Таким образом, нет доказательств того, что животные играют роль в распространении SARS-CoV-2 cреди людей в текущий период пандемии. Вспышки среди людей вызваны передачей вируса от человека к человеку, и, исходя из информации, доступной на сегодняшний день, риск распространения COVID-19 от животных считается низким. Необходимы дополнительные исследования, чтобы понять, как может COVID-19 затронуть животных самых разных видов и насколько велики риски передачи инфекции от них людям.

Ключевые слова: COVID-19, SARS-CoV-2, зооноз, коронавирусы, летучие мыши, дикие и домашние животные.

\section{COVID-19 AS A ZOONOTIC INFECTION}

Kulichenko A.N., Maletskaya O.V., Sarkisyan N.S., Volynkina A.S.

Stavropol Plague Control Research Institute, Stavropol, Russian Federation

Abstract. Here we discuss the issues for attributing the new coronavirus infection COVID-19 to zoonoses based on the data on probable origin of the SARS-CoV-2 virus, the possible formation of its reservoir in animals (bats) as well as human susceptibility. Today, the dominant point of view is that the outbreak of COVID-19 arose as a result of the SARS-CoV-2 coronavirus overcoming the interspecies barrier, acquiring ability to infect and spread in human population. Comparative phylogenetic analysis at the molecular level showed that SARS-CoV-2 is genetically closest to bat coronaviruses, particularly to the RmYN02 and RaTG13 strains isolated from the horseshoe bat, a species considered to be the main host of SARS$\mathrm{CoV}$ and MERS-CoV coronaviruses. The ability of the SARS-CoV-2 coronavirus to infect various wild animal has been

\section{Адрес для переписки:}

Саркисян Нушик Сааковна

355035, Россия, г. Ставрополь, ул. Советская, 13-15, ФКУЗ

Ставропольский противочумный институт Роспотребнадзора.

Тел.: 8 (962) 425-01-29. Факс: 8 (865) 226-03-12.

E-mail: nyshik25@yandex.ru

\section{Для цитирования:}

Куличенко А.Н., Малецкая О.В., Саркисян Н.С., Волынкина A.C. COVID-19 как зоонозная инфекция // Инфекция и иммунитет. 2021. Т. 11, № 4. C. 617-623. doi: 10.15789/2220-7619-CAA-1621

\section{Contacts:}

Nushik S. Sarkisyan

355035, Russian Federation, Stavropol, Sovetskaya str., 13-15

Stavropol Plague Control Research Institute.

Phone: +7 (962) 425-01-29. Fax: 8 (865) 226-03-12.

E-mail: nyshik25@yandex.ru

\section{Citation:}

Kulichenko A.N., Maletskaya O.V., Sarkisyan N.S., Volynkina A.S. COVID-19 as a zoonotic infection // Russian Journal of Infection and Immunity = Infektsiya i immunitet, 2021, vol. 11, no. 4, pp. 617-623. doi: 10.15789/22207619-CAA-1621

DOI: http://dx.doi.org/10.15789/2220-7619-CAA-1621 
revealed. SARS-CoV-2 has been found in minks on farms in the Netherlands with mortality rates ranging from 1.2 to $2.4 \%$. While infecting rhesus monkeys with the SARS-CoV-2, it resulted in productive infection and detected viremia. Cats have been found to be susceptible hosts for the human SARS-CoV-2 virus. A likely explanation for this lies in the high similarity between the human and feline counterpart of the ACE2 receptor. It has been shown that dogs can become infected but transmit no virus to other animals. To date, over the entire period of the pandemic the World Organization for Animal Health provides no information about cases of human infection transmitted from pets. Thus, there is no evidence that animals play a role in the spread of SARS-CoV-2 among people during the current period of the pandemic. Human outbreaks are caused by human-to-human virus transmission, and based on the currently available information, the risk of spreading COVID-19 from animals is considered low. More research is needed to understand how COVID-19 can affect animals of a wide variety of species and how big might be the risks of infection transmission from them to humans.

Key words: COVID-19, SARS-CoV-2, zoonosis, coronaviruses, bats, wild and domestic animals.

Восприимчивость организма к инфекциям определяется как его способность реагировать на патогенный микроорганизм возникновением болезни или носительства возбудителя инфекции. Выделяют две группы факторов, обеспечивающих невосприимчивость индивидуума к возбудителям инфекции: факторы неспецифической (врожденной) резистентности и специфический (приобретенный) иммунитет. Механизмы естественной резистентности и адаптивного иммунитета определяет чувствительность организма к конкретному патогену, в том числе и в плане возможного преодоления им межвидового барьера.

В отечественной литературе для обозначения болезней животных, к которым восприимчив человек, используют понятие «зоонозы» («зооантропонозы»). Инфекции, обозначаемые этим термином, эволюционно сформировались в результате адаптации их возбудителей к обитанию не только в организмах животных, но и человека. Термин «зооантропонозы», по мнению Б.Л. Черкасского [5], теоретически более точно выражает сущность болезней, которыми человек заражается от животных. Однако термин «зоонозы», обозначающий группу инфекционных (паразитарных) болезней, резервуаром возбудителей которых являются животные, но к которым восприимчив человек, получил сегодня широкое распространение в мире и официально принят Всемирной организацией здравоохранения (ВО3) и Продовольственной и сельскохозяйственной организацией ООН (Food and Agriculture Organization, FAO).

К зоонозам относят большинство инфекционных болезней, ставших в последние десятилетия причинами чрезвычайных эпидемических ситуаций (болезнь Эбола, лихорадка Зика и др.). По оценкам ВО3, более $75 \%$ новых заболеваний, обнаруженных за последнее десятилетие, имеют зоонозное происхождение [4].

Глобальное распространение возбудителя COVID-19 - SARS-CoV-2 - обусловило необходимость всеобъемлющего изучения его природы. Коронавирусы широко известны как возбудители инфекционных болезней животных и птиц. Способность их инфицировать новых хозяев привела к переходу коронавирусов с диких млекопитающих на человека и возникновению вспышек SARS и MERS. Сегодня преобладает точка зрения, что вспышка COVID-19 возникла в результате преодоления коронавирусом SARS-CoV-2 видового барьера, приобретения способности инфицировать человека и распространяться в человеческой популяции.

Предположительно, изначально источником коронавируса SARS-CoV-2 являлось дикое животное, от которого произошло инфицирование человека [18, 20, 32]. Первые больные были выявлены в г. Ухань (провинция Хубэй, Китай) и, как считается, имели общее место заражения - оптовый рынок южно-китайских морепродуктов, где для употребления в пищу предлагают продукты из различных диких и домашних животных, в том числе не прошедших термическую обработку: птиц, летучих мышей, змей, ящеров, черепах, ежей, барсуков [15, 18, 21, 27, 28, 46, 47]. В дальнейшем новый коронавирус распространялся путем передачи его от человека к человеку. Использование вирусом SARSCoV-2 в качестве биологических хозяев и естественных резервуаров различных видов животных, а также восприимчивость к нему человека позволяет отнести COVID-19 к зоонозам.

Новый коронавирус SARS-CoV-2 (2019-nCoV) относится к отряду Nidovirales, семейству Coronaviridae, подсемейству Orthocoronavirinae, к роду Betacoronavirus, к которому также принадлежат коронавирусы SARS-CoV и MERS-CoV. Коронавирусы SARS-CoV-2 и SARS-CoV относятся к подроду Sarbecovirus, включающему ряд коронавирусов, обнаруженных у летучих мышей, в том числе у подковообразных летучих мышей (род Rhinolophus).

Коронавирус SARS-CoV-2 на нуклеотидном уровне на 88-89\% имеет сходство с двумя коронавирусами летучих мышей (bat-SL-CoVZC45 и bat-SL-CoVZXC21), на 50-51,8\% - с коронавирусом MERS-CoV и на 79\% идентичен вирусу SARS-CoV [9, 13, 16, 17, 29].

Сравнительный филогенетический анализ показал, что SARS-CoV-2 генетически более бли- 
зок к коронавирусам летучих мышей, в частности к штаммам Bat CoV RmYN02 и Bat CoV RaTG13 (96\% сходства), изолированным от подковообразной летучей мыши - вида летучих мышей, считающегося основным хозяином коронавирусов SARS-CoV и MERS-CoV [29, 30, 36, 37]. Большинство коронавирусов подрода Sarbecovirus выделены от летучих мышей рода Rhinolophus.

Появление новых коронавирусов и широкий круг их хозяев, вероятно, связаны с более высокой частотой генетических рекомбинаций и мутаций в области RBD гена S, а также высокой частотой ошибок при репликации вируса по сравнению с другими РНК-содержащими вирусами [10, 35, 42].

\section{Вероятные носители нового коронавируса SARS-CoV-2}

Летучие мыши - идеальный резервуар для коронавирусов, поскольку вирусы постоянно циркулируют в их популяции, не вызывая симптомов инфекционного заболевания. Обитая в лесах, они передают вирус различным хозяевам, с которыми контактируют [14]. В Китае их продают не только для пищевых целей на рынках живых животных, но и для использования в традиционной китайской медицине. Летучие мыши изначально были резервуаром для SARS$\mathrm{CoV}$ [24] и SARSr-CoV [16, 45], поэтому, вероятно, они стали резервуаром и SARS-CoV-2 [11, 38, 43, 49, 50].

Предполагается участие других промежуточных хозяев - панголинов, которые обеспечивают передачу SARS-CoV-2 человеку [8]. Анализ последовательностей генома показал, что коронавирусы панголинов принадлежат к двум филогенетическим линиям, и одна линия имеет 97,4\% аминокислотной идентичности с рецептор-связывающим доменом (RBD) $\mathrm{S}$-белка коронавируса с аналогичным участком белка SARS-CoV-2 [8]. Не исключено также, что в качестве промежуточного хозяина нового коронавируса могут выступать другие виды диких животных, кроме панголинов и летучих мышей.

\section{Способность коронавируса SARS-CoV-2 инфицировать различные виды диких животных}

Коронавирусы имеют широкий спектр животных-хозяев, целый ряд видов животных являются носителями этих патогенов, и лишь у некоторых из них выявляется тяжелая инфекция [7].

Известно, что коронавирусы $(\mathrm{CoV})$ способны заражать человека, а также домашних и диких животных, в большинстве случаев инфек- ция имеет субклиническое течение [20, 25, 39]. Болезнь может проявляться различными симптомами, характерными для энтерита или поражений верхних дыхательных путей [12].

Коронавирусы SARS-CoV и SARS-CoV-2 (2019-nCoV) используют белок ACE2 в качестве рецептора проникновения в клетку [50]. Из-за мутации в области RBD гена S патогенность и трансмиссивность коронавирусов могут изменяться и усиливаться, диапазон хозяев может расширяться [10].

SARS-CoV-2 был обнаружен у норок на фермах в Дании, Италии, Нидерландах, Испании, Швеции и США [33]. В Дании, по состоянию на 8 ноября 2020 г., вирус был обнаружен на 229 (20\%) из 1140 норковых ферм в стране. Смертность составила от 1,2 до 2,4\% (в основном - беременные самки), у большинства вскрытых норок была выявлена интерстициальная пневмония [34]. Вариант коронавируса, у которого выявлены 4 аминокислотные замены в белке $S$, встречался только у норок и работников норковых ферм [22, 23]. Пока нет научно обоснованных данных о передаче вируса от норок человеку или наоборот.

При инфицировании коронавирусом SARSCoV-2 макак-резусов обнаружена продуктивная инфекция, при этом наибольшее количество вируса SARS-CoV-2 выявляли в мазках из зева/носа [31]. Филогенетический анализ показал, что мембранный белок ACE2 (рецептор для проникновения в клетку коронавируса SARS-CoV-2) у макак (Macaca mulatta) и шимпанзе (Pan troglodytes) наиболее близки к человеческому АCE2 (94,9-99\% нуклеотидной идентичности) [41].

Результаты исследований [44] указывают на наличие зоонозной основы COVID-19 вследствие циркуляции вируса между различными видами позвоночных и людьми (рис.).

Особый интерес вызывает вопрос о возможности заражения людей от домашних питомцев - кошек и собак. Сейчас становится ясно, что кошки являются восприимчивыми хозяевами человеческого вируса SARS-CoV-2. Вероятное объяснение этому кроется в высокой степени сходства между человеческими и кошачьими формами рецептора АCE2. Филогенетический анализ показал, что белок ACE2 домашней кошки (Felis catus) близок к человеческому белку АCE2 с общей идентичностью нуклеотидной последовательности 85,2\% [41].

Целый ряд публикаций подтверждает возможность заражения кошек в лабораторных условиях и передачи возбудителя инфекции среди сородичей $[1,33]$.

Подтверждено, что собаки могут заразиться, но не могут передавать вирус другим собакам. При исследовании 4000 образцов биоматериала 


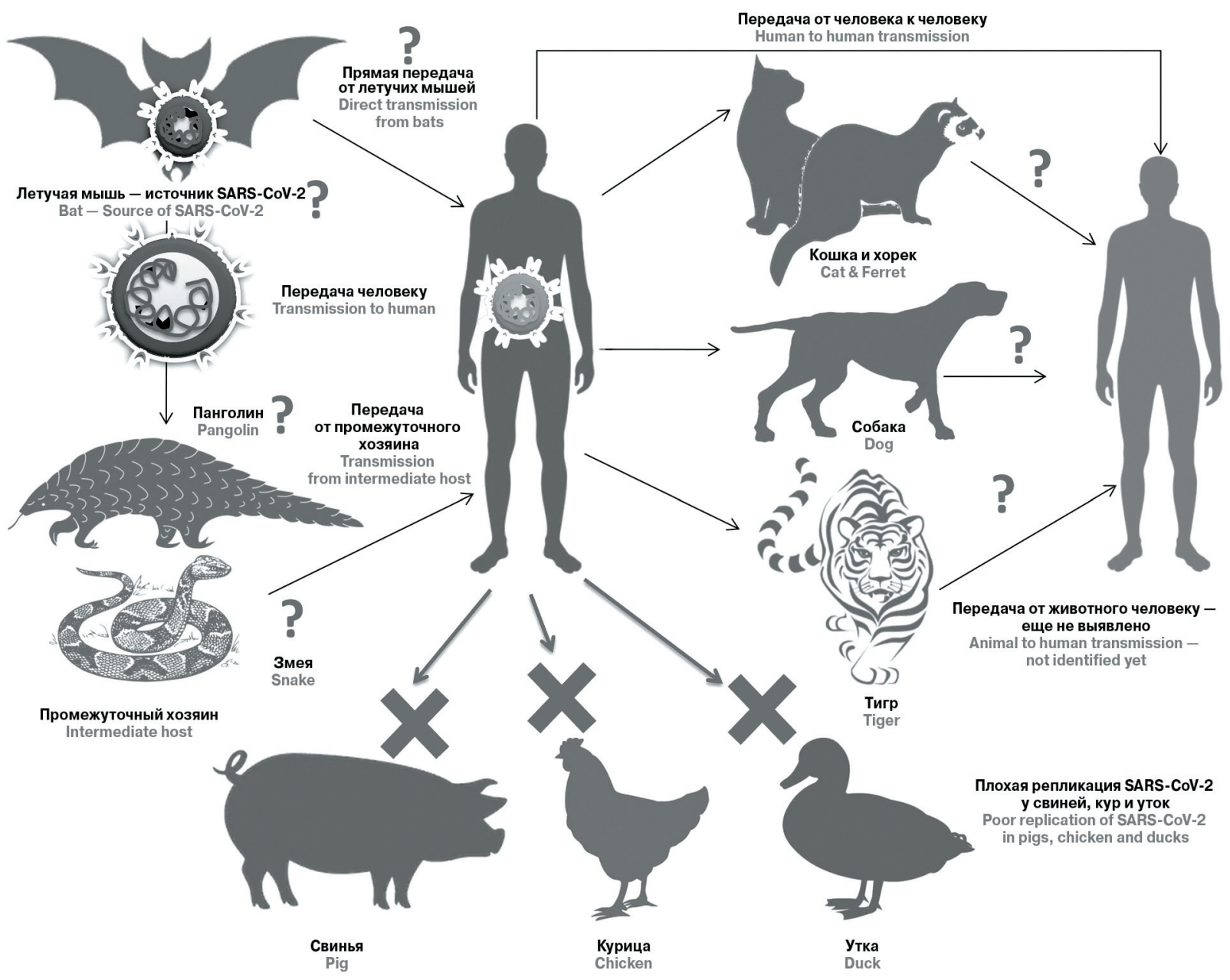

Рисунок. Зоонозные связи SARS-CoV-2 [44]

Figure. Zoonotic links for SARS-CoV-2 [44]

от собак, кошек и лошадей из мест, где происходила передача SARS-CoV-2 у людей, не было выявлено маркеров вируса, что позволяет предположить низкую вероятность передачи вируса от людей животным [19]. К выводу, что собаки и кошки не играют никакой роли в распространении коронавируса SARS-CoV-2, пришли также эксперты из Института Фридриха Леффлера (Грайфсвальд). Было высказано предположение, что, даже если домашние питомцы оказались инфицированы, это не означает, что вирус может размножаться в организме животного и выводиться наружу через слюну или экскременты [3].

Всемирная организация по охране здоровья животных за весь период пандемии не располагает сведениями о случаях заражения человека от домашних питомцев [2].

\section{Заключение}

Естественным резервуаром и источником нового коронавируса SARS-CoV-2 предположительно являются летучие мыши, а инфицирование людей произошло, возможно, через про- межуточного хозяина [26]. В качестве промежуточных хозяев могут выступать панголины, хорьки, змеи [6, 12, 40, 48, 49].

Если первоначально SARS-CoV-2 передался от животных человеку, то затем основным способом передачи COVID-19 среди людей стала передача вируса от человека к человеку [18, 20, 32]. Ранее переход коронавирусов с диких млекопитающих на человека привел к возникновению вспышек SARS и MERS, но они не получили столь масштабного распространения, поскольку отсутствовала возможность воздушно-капельного пути передачи их возбудителей (аэрогенный механизм).

В текущий период пандемии нет доказательств того, что животные играют роль в распространении SARS-CoV-2 среди людей. Вспышки болезни вызваны передачей вируса от человека к человеку, и в соответствии с доступной на сегодняшний день информацией риск распространения COVID-19 с участием животных считается низким. Необходимы дополнительные исследования, чтобы понять, как SARS-CoV-2 может поражать животных разных видов, а также чтобы 
определить возможность формирования новых резервуаров вируса и оценить, насколько велики риски передачи возбудителя инфекции от различных животных людям.

Сегодня нет доказательств того, что домашние животные (кошки, собаки) легко заражаются SARS-CoV-2 в естественных условиях, хотя предположительно в редких случаях они могут инфицироваться от людей, но не передают (практически не передают) вирус людям.
Антропогенный потенциал установлен у нескольких возбудителей зоонозных коронавирусных инфекций, таких как SARS, MERS, а теперь и COVID-19. Возникновение новых подобных инфекций неизбежно в будущем. Вспышка COVID-19 - еще один важный пример, доказывающий существование тесного и прямого взаимодействия людей и животных, что потенциально может привести к возникновению опасных пандемий зоонозного характера.

\section{Список литературы/References}

1. СМИ сообщили о заражении коронавирусом двух кошек в США// РБК. 2020. [The media reported on the infection of two cats with coronavirus in the USA. RBC, 2020. (In Russ.)] URL: https://www.rbc.ru/rbcfreenews/5ea101369a79476145076469 (03.10.2020)

2. Соболева И. Хвостатые на карантине: почему зараженные COVID-19 кошки не опасны для хозяев // Москва24. 2020. [Soboleva I. Animals on quarantine: why cats infected with COVID-19 are not dangerous for their owners. Moskva24, 2020. (In Russ.)] URL: https://www.m24.ru/articles/obshchestvo/27052020/156734?utm_source=CopyBufhttps://www.m24?utm_ source $=$ CopyBuf $(03.10 .2020)$

3. Фройнд А., Позднякова Н. Кошки и собаки не могут заразить человека коронавирусом. А заразиться сами? // Deutsche Welle. 2020. [Freund A., Pozdnyakova N. Cats and dogs can't infect humans with coronavirus. And get yourself infected? Deutsche Welle, 2020. (In Russ.)] URL: https://www.dw.com/ru/koshki-i-sobaki-ne-mogut-zarazit-cheloveka-koronavirusom/a-54430702 (03.10.2020)

4. Хусаинов Р.Х. Зоонозные заболевания // Medical Insider. 2018. [Khusainov R.H. Zoonotic diseases. Medical Insider, 2018. (In Russ.)] URL: https://medicalinsider.ru/news/zoonoznye-zabolevaniya/(03.10.2020)

5. Черкасский Б.Л. Руководство по общей эпидемиологии. М.: Медицина, 2001. 560 c. [Cherkassky B.L. Guidelines for general epidemiology. Moscow: Medicine, 2001. 560 p. (In Russ.)]

6. Almendros A. Can companion animals become infected with COVID-19? Vet. Rec., 2020, vol. 186, no. 12, pp. 388-389. doi: $10.1136 / v r . m 1322$

7. Andersen K.G., Rambaut A., Lipkin W.I., Holmes E.C., Garry R.F. The proximal origin of SARS-CoV-2. Nat. Med., 2020, vol. 26, no. 4, pp. 450-452. doi: 10.1038/s41591-020-0820-9

8. Boni M.F., Lemey P., Jiang X., Lam T.T., Perry B.W., Castoe T.A., Rambaut A., Robertson D.L. Evolutionary origins of the SARS-CoV-2 sarbecovirus lineage responsible for the COVID-19 pandemic. Nat. Microbiol., 2020, vol. 5, no. 11, pp. 1408-1417. doi: 10.1038/s41564-020-0771-4

9. Chan J.F., Kok K.H., Zhu Z., Chu H., To K.K., Yuan S., Yuen K.Y. Genomic characterization of the 2019 novel human-pathogenic coronavirus isolated from a patient with atypical pneumonia after visiting Wuhan. Emerg. Microbes Infect., 2020, vol. 9, no. 1, pp. 221-236. doi: 10.1080/22221751.2020.1719902

10. Chen J. Pathogenicity and transmissibility of 2019-nCoV-A quick overview and comparison with other emerging viruses. Microbes Infect., 2020, vol. 22, no. 2, pp. 69-71. doi: 10.1016/j.micinf.2020.01.004

11. Cui J., Li F., Shi Z.L. Origin and evolution of pathogenic coronaviruses. Nat. Rev. Microbiol., 2019, vol. 17, no. 3, pp. 181-192. doi: 10.1038/s41579-018-0118-9

12. Dhama K., Patel S.K., Sharun K., Pathak M., Tiwari R., Yatoo M.I. SARS-CoV-2: Jumping the species barrier, lessons from SARS and MERS, its zoonotic spillover, transmission to humans, preventive and control measures and recent developments to counter this pandemic virus. Travel Med. Infect. Dis., 2020, vol. 37. doi: 10.1016/j.tmaid.2020.101830

13. Drexler J.F., Corman V.M., Drosten C. Ecology, evolution and classification of bat coronaviruses in the aftermath of SARS. Antiviral Res., 2014, vol. 101, pp. 45-56. doi: 10.1016/j.antiviral.2013.10.013

14. Fan Y., Zhao K., Shi Z.L., Zhou P. Bat coronaviruses in China. Viruses, 2020, vol. 11, no. 3: 210. doi: 10.3390/v11030210

15. Hu B., Ge X., Wang L.F., Shi Z. Bat origin of human coronaviruses. J. Virol., 2015, vol. 12, pp. 221. doi: 10.1186/s12985-0150422-1

16. Hu B., Zeng L.P., Yang X.L., Ge X.Y., Zhang W., Li B., Xie J.Z., Shen X.R., Zhang Y.Z., Wang N., Luo D.S. Discovery of a rich gene pool of bat SARS-related coronaviruses provides new insights into the origin of SARS coronavirus. PLoS Pathog., 2017, vol. 13, no. 11: e1006698. doi: 10.1371/journal.ppat.1006698

17. Hu D., Zhu C., Ai L., He T., Wang Y., Ye F., Yang L., Ding C., Zhu X., Lv R. Genomic characterization and infectivity of a novel SARS-like coronavirus in Chinese bats. Emerg. Microbes Infect., 2018, vol. 7, no. 1: 154. doi: 10.1038/s41426-018-0155-5

18. Hui D.S., Azhar E., Madani T.A., Ntoumi F., Kock R., Dar O., Ippolito G., Mchugh T.D., Memish Z.A., Drosten C. The continuing 2019-nCoV epidemic threat of novel coronaviruses to global health - the latest 2019 novel coronavirus outbreak in Wuhan, China. Int. J. Infect. Dis., 2020, vol. 91, pp. 264-266. doi: 10.1016/j.ijid.2020.01.009

19. IDEXX SARS-CoV-2 (COVID-19) RealPCR Test. IDEXX. URL: https://www.idexx.com/en/veterinary/reference-laboratories/ idexx-sars-cov-2-covid-19-realpcr-test (03.10.2020)

20. Ji W., Wang W., Zhao X., Zai J., Li X. Cross-species transmission of the newly identified coronavirus 2019-nCoV. J. Med. Virol., 2020a, vol. 92, no. 4, pp. 433-440. doi: 10.1002/jmv.25682

21. Ji W., Wang W., Zhao X., Zai J., Li X. Homologous recombination within the spike glycoprotein of the newly identified coronavirus may boost cross-species transmission from snake to human. J. Med. Virol., 2020, vol. 92, no. 4: 25682. doi: 10.1002/jmv.25682 
22. Kort over kommuner med smittede minkfarme. Fødevarestyrelsen. 2020. URL: https://www.foedevarestyrelsen.dk/Dyr/Dyr-ogCovid-19/Mink-og-COVID-19/Sider/Kort-over-kommuner-med-smittede-minkfarme.aspx (03.10.2020)

23. Lassaunière R., Fonager J., Rasmussen M., Frische A., Strandh Ch. P., Rasmussen T.B., Bøtner A., Fomsgaard A. SARS-CoV-2 spike mutations arising in Danish minkand their spread to humans. URL: https://files.ssi.dk/Mink-cluster-5-short-report_AFO2 (03.10.2020)

24. Li W., Shi Z., Yu M., Ren W., Smith C., Epstein J.H., Wang H., Crameri G., Hu Z., Zhang H. Bats are natural reservoirs of SARSlike coronaviruses. Science, 2005, vol. 310, pp. 676-679. doi: 10.1126/science

25. Li X., Song Y., Wong G., Cui J. Bat origin of a new human coronavirus: there and back again. Sci. China Life Sci., 2020, vol. 63, no. 3, pp. 461-462. doi: 10.1007/s11427-020-1645-7

26. Li X., Zai J., Zhao Q., Nie Q., Li Y., Foley B.T., Chaillon A. Evolutionary history, potential intermediate animal host, and crossspecies analyses of SARS-CoV-2. J. Med. Virol., 2020, vol. 92, no. 6, pp. 602-611. doi: 10.1002/jmv.25731

27. Liu J., Zheng X., Tong Q., Li W., Wang B., Sutter K., Trilling M., Lu M., Dittmer U., Yang D. Overlapping and discrete aspects of the pathology and pathogenesis of the emerging human pathogenic coronaviruses SARS-CoV, MERS-CoV, and 2019-nCoV. J. Med. Virol., 2020, vol. 92, no. 5, pp. 491-494. doi: 10.1002/jmv.25709

28. Lu R., Zhao X., Li J., Niu P., Yang B., Wu H., Wang W., Song H., Huang B., Zhu N. Genomic characterisation and epidemiology of 2019 novel coronavirus: implications for virus origins and receptor binding. Lancet, 2020, vol. 395, no. 10224, pp. $565-574$. doi: 10.1016/S0140-6736(20)30251-8

29. Malik Y.S., Sircar S., Bhat S., Sharun K., Dhama K., Dadar M., Tiwari R., Chaicumpa W. Emerging novel Coronavirus (2019-nCoV)-Current scenario, evolutionary perspective based on genome analysis and recent developments. Vet. Q., 2020, vol. 40, no. 1, pp. 68-76. doi: 10.1080/01652176.2020.1727993

30. Mohd H.A., Al-Tawfiq J.A., Memish Z.A. Middle East respiratory syndrome coronavirus (MERS-CoV) origin and animal reservoir. J. Virol., 2016, vol. 13: 87. doi: 10.1186/s12985-016-0544-0

31. Munster V.J., Feldmann F., Williamson B.N., van Doremalen N., Pérez-Pérez L., Schulz J., Meade-White K., Okumura A., Callison J., Brumbaugh B. Respiratory disease and virus shedding in rhesus macaques inoculated with SARS-CoV-2. Nature, 2020, vol. 585, pp. 268-272. doi: 10.1038/s41586-020-2324-7

32. Nishiura H., Linton N.M., Akhmetzhanov A.R. Initial cluster of novel coronavirus (2019-nCoV) Infections in Wuhan, China is consistent with substantial human-to-human transmission. JCM, 2020, vol. 9, no. 2, pp. 488. doi: 10.3390/jcm9020488

33. OIE. COVID-19: Events in animals. URL: https://www.oie.int/en/what-we-offer/emergency-and-resilience/covid-19/(03.10.2020)

34. Oreshkova N., Molenaar R.J., Vreman S., Harders F., Oude Munnink B.B., Hakze-van der Honing R.W., Gerhards N., Tolsma P., Bouwstra R., Sikkema R.S., Tacken M.G., de Rooij M.M., Weesendorp E., Engelsma M.Y., Bruschke C.J., Smit L.A., Koopmans M., van der Poel W.H., Stegeman A. SARS-CoV-2 infection in farmed minks, the Netherlands, April and May 2020. Euro Surveill., 2020, vol. 25, no. 23: 2001005. doi: 10.2807/1560-7917.ES.2020.25.23.2001005

35. Patel A., Jernigan D.B.; 2019-nCoV CDC Response Team. Initial public health response and interim clinical guidance for the 2019 novel coronavirus outbreak - United States. MMWR Morb. Mortal Wkly Rep., 2020, vol. 69, no. 5, pp. 140-146. doi: 10.1111/ ajt. 15805

36. Ramadan N., Shaib H. Middle East respiratory syndrome coronavirus (MERS-CoV): a review. Germs., 2019, vol. 9, no. 1, pp. 35-42. doi: 10.18683/germs.2019.1155

37. Ren L.L., Wang Y.M., Wu Z.Q., Xiang Z.C., Guo L., Xu T., Jiang Y.Z., Xiong Y., Li Y.J., Li H., Fan G.H., Gu X.Y., Xiao Y., Gao H., Xu J.Y., Yang F., Wang X.M., Wu C., Chen L., Liu Y.W., Liu B., Yang J., Wang X.R., Dong J., Li L., Huang C.L., Zhao J.P., Hu Y., Cheng Z.S., Liu L.L., Qian Z.H., Qin C., Jin Q., Cao B., Wang J.W. Identification of a novel coronavirus causing severe pneumonia in human: a descriptive study. Chin. Med. J. (Engl.), 2020, vol. 133, no. 9, pp. 1015-1024.

38. Rodriguez-Morales A.J., Bonilla-Aldana D.K., Balbin-Ramon G.J., Rabaan A.A., Sah R., Paniz-Mondolfi A., Pagliano P., Esposito S. History is repeating itself, a probable zoonotic spillover as a cause of an epidemic: the case of 2019 novel Coronavirus. Infez. Med., 2020, vol. 28, no. 1, pp. 3-5.

39. Salata C., Calistri A., Parolin C., Palu G. Coronaviruses: a paradigm of new emerging zoonotic diseases. Pathog. Dis., 2019, vol. 77, no. 9: ftaa006. doi: 10/1093/femspd/ftaa006

40. Shi J., Wen Z., Zhong G., Yang H., Wang C., Huang B., Liu R., He X., Shuai L., Sun Z., Zhao Y., Liu P., Liang L., Cui P., Wang J., Zhang X., Guan Y., Tan W., Wu G., Chen H., Bu Z. Susceptibility of ferrets, cats, dogs, and other domesticated animals to SARScoronavirus 2. Science, 2020, vol. 368, no. 6494, pp. 1016-1020. doi: 10.1126/science.abb7015

41. Stout A.E., André N.M., Jaimes J.A., Millet J.K., Whittaker G.R. Coronaviruses in cats and other companion animals: where does SARS-CoV-2/COVID-19 fit? Vet. Microbiol., 2020, vol. 247: 108777. doi: 10.1016/j.vetmic.2020.108777

42. Su S., Wong G., Shi W., Liu J., Lai A.C.K., Zhou J., Liu W., Bi Y., Gao G.F. Epidemiology, genetic recombination, and pathogenesis of Coronaviruses. Trends Microbiol., 2016, vol. 24, no. 6, pp. 490-502. doi: 10.1016/j.tim.2016.03.003

43. Tang X.C., Zhang J.X., Zhang S.Y., Wang P., Fan X.H., Li L.F., Li G., Dong B.Q., Liu W., Cheung C.L., Xu K.M., Song W.J., Vijaykrishna D., Poon L.L., Peiris J.S., Smith G.J., Chen H., Guan Y. Prevalence and genetic diversity of coronaviruses in bats from China. J. Virol., 2006, vol. 80, no. 15, pp. 7481-7490. doi: 10.1128/JVI.00697-06

44. Tiwari R., Dhama K., Sharun K., Iqbal Yatoo M., Malik Y.S., Singh R., Michalak I., Sah R., Bonilla-Aldana D.K., RodriguezMorales A.J. COVID-19: animals, veterinary and zoonotic links. Vet. Q., 2020, vol. 40, no. 1, pp. 169-182. doi: 10.1080/01652176. 2020.1766725

45. Wang N., Li S.Y., Yang X.L., Huang H.M., Zhang Y.J., Guo H., Luo C.M., Miller M., Zhu G., Chmura A.A. Serological evidence of bat SARS-related coronavirus infection in humans, China. Virol. Sin., 2018, vol. 33, pp. 104-107. doi: 10.1007/s12250-018-0012-7

46. Wang W., Tang J., Wei F. Updated understanding of the outbreak of 2019 novel coronavirus (2019-nCoV) in Wuhan, China. J. Med. Virol., 2020, vol. 92, no. 4, pp. 441-447. doi: 10.1002/jmv.25689

47. Wu F., Zhao S., Yu B., Chen Y.M., Wang W., Song Z.G., Hu Y., Tao Z.W., Tian J.H., Pei Y.Y., Yuan M.L., Zhang Y.L. A new coronavirus associated with human respiratory disease in China. Nature, 2020, vol. 579, no. 7798, pp. 265-269. doi: 10.1038/ s41586-020-2008-3 
48. Zhang Q., Zhang H., Gao J., Huang K., Yang Y., Hui X., He X., Li C., Gong W., Zhang Y., Zhao Y., Peng C., Gao X., Chen H., Zou Z., Shi Z.L., Jin M. A serological survey of SARS-CoV-2 in cat in Wuhan. Emerg. Microbes Infect., 2020, vol. 9, no. 1, pp. 2013-2019. doi: 10.1080/22221751.2020.1817796

49. Zhang T., Wu Q., Zhang Z. Pangolin homology associated with 2019-nCoV. BioRxiv, 2020. doi: 10.1101/2020.02.19.950253

50. Zhou P., Yang X.L., Wang X.G., Hu B., Zhang L., Zhang W., Si H.R., Zhu Y., Li B., Huang C.L., Chen H.D., Chen J., Luo Y., Guo H., Jiang R.D., Liu M.Q., Chen Y., Shen X.R., Wang X., Zheng X.S., Zhao K., Chen Q.J., Deng F., Liu L.L., Yan B., Zhan F.X., Wang Y.Y., Xiao G.F., Shi Z.L. A pneumonia outbreak associated with a new coronavirus of probable bat origin. Nature, 2020, vol. 579, no. 7798, pp. 270-273. doi: 10.1038/s41586-020-2012-7

\section{Авторы:}

Куличенко А.Н., д.м.н., профессор, член-корреспондент РАН, директор ФКУЗ Ставропольский противочумный институт Роспотребнадзора, г. Ставрополь, Россия;

Малецкая О.В., д.м.н., профессор, зам. директора по научной и противоэпидемической работе ФКУЗ Ставропольский противочумный институт Роспотребнадзора, г. Ставрополь, Россия;

Саркисян Н.С., к.м.Н., врач клинической лабораторной диагностики, зав. отделом консультационно-профилактической работы ФКУЗ Ставропольский противочумный институт Роспотребнадзора, г. Ставрополь, Россия

Волынкина А.С., к.б.н., зав. лабораторией диагностики вирусных инфекций ФКУЗ Ставропольский противочумный институт Роспотребнадзора, г. Ставрополь, Россия.

\section{Authors:}

Kulichenko A.N., PhD, MD (Medicine), Professor, RAS Corresponding Member, Director of the Stavropol Plague Control Research Institute, Stavropol, Russian Federation; Maletskaya O.V., PhD, MD (Medicine), Professor, Deputy Director for Scientific and Anti-Epidemic Work, Stavropol Plague Control Research Institute, Stavropol, Russian Federation;

Sarkisyan N.S., PhD (Medicine), Doctor of Clinical Laboratory Diagnostics, Head of the Department of Consulting and Preventive Work, Stavropol Plague Control Research Institute, Stavropol, Russian Federation;

Volynkina A.S., PhD (Biology), Head of the Laboratory for Diagnostics of Viral Infections, Stavropol Plague Control Research Institute, Stavropol, Russian Federation.
Поступила в редакцию 28.10.2020

Отправлена на доработку 10.01.2021

Принята к печати 30.05.2021
Received 28.10.2020

Revision received 10.01.2021

Accepted 30.05.2021 